\title{
Understanding Traffic Accidents among Young Drivers in Qatar
}

\author{
Faris Tarlochan ${ }^{1, *} \mathbb{0}$, Mohamed Izham Mohamed Ibrahim ${ }^{2} \mathbb{D}$ and Batool Gaben ${ }^{1}$ \\ 1 Department of Mechanical and Industrial Engineering, Qatar University, Doha P.O. Box 2713, Qatar; \\ bg1102639@student.qu.edu.qa \\ 2 Department of Clinical Pharmacy and Practice, College of Pharmacy, QU Health, Qatar University, \\ Doha P.O. Box 2713, Qatar; mohamedizham@qu.edu.qa \\ * Correspondence: faris.tarlochan@qu.edu.qa
}

check for updates

Citation: Tarlochan, F.; Ibrahim, M.I.M.; Gaben, B. Understanding Traffic Accidents among Young Drivers in Qatar. Int. J. Environ. Res. Public Health 2022, 19, 514. https:// doi.org/10.3390/ijerph19010514

Academic Editor: Paul B.

Tchounwou

Received: 24 November 2021

Accepted: 31 December 2021

Published: 4 January 2022

Publisher's Note: MDPI stays neutral with regard to jurisdictional claims in published maps and institutional affiliations.

Copyright: () 2022 by the authors. Licensee MDPI, Basel, Switzerland. This article is an open access article distributed under the terms and conditions of the Creative Commons Attribution (CC BY) license (https:// creativecommons.org/licenses/by/ $4.0 /)$.

\begin{abstract}
Young drivers are generally associated with risky driving behaviors that can lead to crash involvement. Many self-report measurement scales are used to assess such risky behaviors. This study is aimed to understand the risky driving behaviors of young adults in Qatar and how such behaviors are associated with crash involvement. This was achieved through the usage of validated self-report measurement scales adopted for the Arabic context. A nationwide cross-sectional and exploratory study was conducted in Qatar from January to April 2021. Due to the Covid-19 pandemic, the survey was conducted online. Therefore, respondents were selected conveniently. Hence, the study adopted a non-probability sampling method in which convenience and snowball sampling were used. A total of 253 completed questionnaires were received, of which $57.3 \%$ were female, and $42.7 \%$ were male. Approximately $55.8 \%$ of these young drivers were involved in traffic accidents after obtaining their driving license. On average, most young drivers do have some risky driving behavior accompanied by a low tendency to violate traffic laws, and their driving style is not significantly controlled by their personality on the road. The older young drivers are more involved in traffic accidents than the younger drivers, i.e., around 1.5 times more likely. Moreover, a young male driver is 3.2 times less likely to be involved in traffic accidents than a female driver. In addition, males are only 0.309 times as likely as females to be involved in an accident and have approximately a 70\% lower likelihood of having an accident versus females. The analysis is complemented with the association between young drivers' demographic background and psychosocial-behavioral parameters (linking risky driving behavior, personality, and obligation effects on crash involvement). Some interventions are required to improve driving behavior, such as driving apps that are able to monitor and provide corrective feedback.
\end{abstract}

Keywords: risky driving behavior; traffic accidents; traffic violations; young drivers; traffic safety

\section{Introduction}

Road accidents have become one of the most common causes of morbidity and mortality, especially in children and young adults aged 5-29 years [1]. According to the World Health Organization (WHO) [1], approximately 1.3 million die each year due to road accidents, resulting in a loss of around 3\% of the country's gross domestic product (GDP). In the United States, the estimated economic loss to society due to road accidents amounted to $\$ 242$ billion in 2010 [2]. There are several contributors that lead to road accidents, one of which is human error. The following are some of the risk factors identified by the WHO related to human errors: (1) speeding-every $1 \%$ increase in the mean speed increases fatal crash risk probability by $4 \%$, (2) seatbelt usage-usage will reduce fatality by $45-50 \%$ for front-seat occupants, (3) driving under the influence of psychotropic substances-can increase risk by about five times, and (4) distracted driving-usage of mobile phones can increase the risk of an accident by 4 folds. Many studies have been published supporting the claim by the $\mathrm{WHO}$, indicating that risky driving behaviors are one of the leading causes of road accidents [3-9]. 
It was also reported by the $\mathrm{WHO}[1]$ that $73 \%$ of all road accident deaths occur in young men aged 25 years and below. This is supported by Scott-Parker et al. [10] that driving violations such as speeding, a form of risky behavior, are very common among young drivers. Fu et al. [11] found that young drivers tend to tailgate vehicles in front of them, while Fernandes et al. [12] showed that young drivers tend to overtake vehicles dangerously. Driver inattention among young drivers is another significant contributor to crashes [13]. Inattention can also be caused by distractions such as mobile phone usage, eating, drinking, and too many people in vehicles [14-19]. Such risky behaviors are also evident among young drivers in Qatar. In a study conducted by Awadalla et al. [20], it was found that young drivers in Qatar have higher risks of accidents owing to their risky driving behaviors. In addition, it was found that male drivers had a 10 times higher road mortality than the general population. This was supported by a study by Soliman et al. [21], who found that men under the age of 25 in Qatar, with a low level of education and who use a 4-wheel-drive (4WD) had the worst driving errors, violations, and lapses. Besides this, the importance framing the local accident database with an international approach is crucial, as stated by Casao-Sanz et al. [22]. From Qatar's Traffic Department, the total number of road fatalities in 2016 was 178, while in 2017, the number was 177, and in 2018 it stood at 168 . The main reason for accidents, according to the report, was reckless driving, which is 42.4 percent of the total cases. To support this, in a separate study [23], drivers in Qatar have been identified as high risk for road traffic injuries.

Driving is a complex activity that requires (i) cognitive tasks, such as visual and perceptual stimuli and information processing, and (ii) physical tasks: vehicle control in response to a dynamic environment [24]. Several tools have been used to study and assess driving behavior, and actual road assessment is the ideal approach. However, this endeavor can be costly, stressful, and difficult to conduct for several reasons [24]. One of the easiest and fastest exploratory research approaches is the use of self-report instrument tools. To study risky driving behavior, researchers worldwide have used self-report instrument tools such as the Manchester Driver Behavior Questionnaire (DBQ) [25], Driver Attitude Questionnaire (DAQ) [26], Driving Skill Inventory [27], and Behavior of Novice Young Drivers scale (BNYDS) [28]. Self-reporting instrumental tools are preferred by researchers because they are easy to use and cheap [29]. Among these tools, DBQ is the most widely used [30]. This tool was developed to measure two dimensions: (a) violations such as speeding, crossing red lights, aggressive stance, and (b) errors such as misjudgment [30]. However, DBQ has recently drawn criticism because of its poor predictive ability [31,32] and the omission of other recent factors that contribute to crash accidents [30]. Many crash-contributing factors, such as the usage of mobile phones, fatigue, and time pressure, are not well captured by existing self-report tools. BNYDS was effective when studying novice young drivers [28]; however, this self-report tool is not easily transferrable to another international driving environment because of the uniqueness of the tool, which was developed for Queensland, Australia [30]. Al Reesi et al. [30] argued that there is a need to design self-report tools that are culturally specific, which led to the development of the first Arab self-report tool, which is a modified version of DBQ and BNYDS [30]. The tool was validated and used to study risky driving behaviors among young Omani drivers.

Personality traits, such as aggression, anxiety, and sensation seeking, are also possible predictors of risky driving behavior [33-36]. A study by Ulleberg et al. and Spano et al. [33,34] showed that young adult drivers showed more difficulty in self-regulation in relation to personality traits. In a separate study by the Society of Risk Analysis [35], it was found that an angry personality leads to aggressive driving behavior, as reported in Roseborough et al. [36]; they developed a model that showed that drivers' belief in an unjust world leads to driving injustice in the form of aggressive retaliatory driving. Such studies have demonstrated that personality traits are important factors to consider.

In view of the above, an exploratory study was conducted to understand the driving behavior of young adults in Qatar and its relation to traffic accidents by addressing the following hypothesis: 
Hypothesis 1. Positive personality and positive obligation towards traffic laws have a significant positive impact on safe driving behavior.

Hypothesis 2. Positive personality and positive obligation towards traffic laws have a significant impact on reducing accident involvement.

Hypothesis 3. Each driving behavior factor $(D B)$ has a significant impact on accident involvement.

Hypothesis 4. Demographics traits have significant positive impacts on accident involvement.

Hence, the objectives of this study are to (i) explore the validity and reliability of the tool by Al Reesi [30] in the Qatari context and (ii) use the validated modified self-report to study the risky driving behavior of young drivers in Qatar and its correlation to traffic accidents by addressing the above hypotheses.

\section{Methods}

\subsection{Study Design}

A nationwide cross-sectional and exploratory study was conducted in Qatar from January to April 2021 to measure risky driving behavior, personality, and obligation to traffic laws while driving among young drivers in Qatar. As stated in the previous section, the aim is to develop connections between drivers' behavior, obligation towards traffic laws, and personality with traffic accidents. The study was approved by the institutional review board (ethics committee) of Qatar University.

\subsection{Study Population and Sampling}

The total population of Qatar is approximately 2.6 million as of June 2021. The study population was targeted to all young drivers in Qatar from 18 to 25 years, both males and females, which comprise around 300,000 people ( $11 \%$ of the total population). Based on this, the sample size was calculated using the Raosoft ${ }^{\circledR}$ sample size calculator (http: / / www.raosoft.com/samplesize.html accessed on 30 May 2020). At the 95\% confidence level, $5 \%$ margin of error, and with a response distribution of $50 \%$, the estimated sample size for this study was 384. A 50\% sample was added for the possibility of non-responders, which gave a final sample size of 576. Due to the Covid-19 pandemic, it was impossible to meet the participants physically; as such, the survey was conducted online. We distributed the survey through email blasts, social media, and student leaders. Therefore, respondents were selected conveniently. Hence, the study adopted a non-probability sampling method in which convenience and snowball sampling were used $[30,37]$.

\subsection{Outcome Measures and Instrument Validation Process}

The survey adopted in this study was a validated questionnaire generated by Al Reesi et al. [30], which was a modification of DBQ and BNYDS. The survey was conducted in two languages, English and Arabic. For the Arabic version, a couple of rounds of forwardbackward translations were performed to ensure that the original meaning and context of the survey were not lost. The survey had a few parts. The initial part was related to participants' socio-demographics, such as age, gender, education level, marital status, ethnicity, working status, nationality, religion, and vehicle ownership. The second part of the survey examined the driving history: (a) learning to drive on-road with or without supervision, (b) driving experience in years, (c) frequency of driving a week, and (d) age at which participants started to learn to drive. The third part of the survey consisted of questions pertaining to seven (7) risky driving behaviors: transient violation, mood driving, speeding, fatigue, distracted driving, seatbelt usage, and tailgating. The fourth and fifth parts of the survey looked at the personality nature and obligation towards traffic laws while driving. The last section of the survey focused on the crash history of the participants. 
The researchers utilized the Qualtrics survey tool for this study since the entire survey was conducted online. The following is a summary of the breakdown of the survey tool:

- Part 1: Socio-demographics (8 questions)

- $\quad$ Part 2: Driving history (5 questions)

- $\quad$ Part 3: Driving behavior (40 questions)

- DB1-Transient Violation (17 questions-related to risky maneuvers such as running over a red light, overtaking from the right-hand side, illegal U-turns, putting other vehicles at risk, etc.)

○ DB2-Mood driving (8 questions-related to getting angry while driving, honking, driving fast when in a bad mood, etc.)

DB3-Speeding (4 questions-related to speed limits)

DB4-Fatigue (3 questions related to tiredness, taking breaks, etc.)

DB5-Distracted driving (4 questions related to mobile usage, eating/drinking while driving)

DB6-Seatbelt usage (two questions related to the usage of seatbelts while driving) DB7-Tailgating (two questions related to driving close to vehicles in front of the driver)

- $\quad$ Part 4: Personality (13 questions)

This part contains questions regarding the persons' personality while driving, such as prediction of driving consequences, worry about making mistakes, worry about offending others on the road, and aggressiveness while driving.

- $\quad$ Part 5: Obligation to follow traffic law (9 questions)

This part seeks to understand the participant's obligation to follow traffic laws while driving. Questions such as the need to follow traffic rules, the importance of some rules, etc.

- Part 6: Traffic Accidents (3 questions)

Q1-Have you ever been in car accidents

Q Q2-How many accidents have you been involved in as a driver since getting your driving license?

Q Q3-From the accidents that you have been involved in, how many were your faults?

\subsection{Data Collection Procedure}

We distributed the survey through email blasts, social media, and student leaders. We managed to obtain 558 respondents; however, after filtering for completeness in responses, a total of 253 responses were identified. This corresponds to a sampling error of $\pm 7 \%$ at a 95\% confidence level. A similar sample size was used by Roseborough et al. [36], and Moataz et al. [38].

\subsection{Pilot Study}

Before the survey was launched, a pilot study was conducted to examine the content validity, readability, and clarity of each item in the survey. A total of 20 participants participated in the pilot study. Slight changes were made to the language to enhance clarity and readability based on the comments received from the participants. The survey was distributed to the target population.

\subsection{Statistical Analysis}

The Statistical Package for the Social Sciences (SPSS) version 27 (IBM Corp. Released 2020. IBM SPSS Statistics for Windows version 27.0. Armonk, NY: IBM Corp.) was used to analyze the data. SPSS was used to conduct a descriptive analysis of the data obtained (mean [standard deviation, SD], median [interquartile range (IQR)], frequency [\%]). This was followed by factorial validity using Cronbach's alpha to measure internal consis- 
tency (interrelatedness of survey items). An alpha coefficient of 0.7 above is considered acceptable [30]. Normality tests were performed for continuous outcome variables. The Mann-Whitney test, Chi-square test, Spearman-rho test, and multiple regression analysis (i.e., linear and logistic) were used. The analysis continues with the association between young drivers' demographic background and psychosocial-behavioral parameters (linking risky driving behavior, personality, and obligation effects on crash involvement). The a priori significance level was set at 0.05 .

\section{Results}

\subsection{Background Characteristics}

Table 1 shows the respondents' background profiles. The majority were female $(n=145,57.3 \%)$ and 21 years old $(n=57,22.5 \%)$. The mean age (with standard deviation, sd) of male and female drivers was 20.59 (2.18) and 21.17 (1.96), respectively, with $p=0.032$ (less than 0.05). There were fewer male drivers than female drivers and significantly younger male than female drivers. In general, most of the respondents $(n=205$, $80 \%$ ) drove their vehicles for at least three days per week. The driving histories of the respondents are listed in Table 2 . It has been reported that they started to learn to drive from 10 to 24 years of age, with a majority of them $(n=89,34.9 \%)$ at the age of 18 , followed by $18.8 \%(n=48)$ at the age of 17 . Approximately $45 \%(n=114)$ admitted that they had driven a car without supervision prior to obtaining a driving license. Other major responses indicated that the car that they were driving belonged to their parents $(n=147,58.1 \%)$, they learned how to drive a car in a driving school $(n=115,45.5 \%)$, and $141(55.7 \%)$ drove a car daily.

Table 1. Young drivers' background characteristics $\left(\mathrm{N}_{\text {total }}=253\right)$.

\begin{tabular}{ccc}
\hline Item & Description & $\boldsymbol{N}, \mathbf{( \% )}$ \\
\hline Gender & Male & $108(42.7)$ \\
& Female & $145(57.3)$ \\
Age & 18 & $43(17.0)$ \\
& 19 & $38(15.0)$ \\
& 20 & $30(11.9)$ \\
& 21 & $57(22.5)$ \\
& 22 & $28(11.1)$ \\
Nationality & 23 & $23(9.1)$ \\
& 24 & $16(6.3)$ \\
Ethnicity & 25 & $18(7.1)$ \\
& Qatari & $144(56.9)$ \\
Education Level & Non-Qatari & $109(43.1)$ \\
& Arab & $217(85.1)$ \\
& Non-Arab & $36(14.9)$ \\
& Secondary & $90(35.6)$ \\
& Tertiary & $163(64.4)$ \\
\hline
\end{tabular}

Table 3 shows the experiences of traffic accident involvement among young drivers. It shows that $55.8 \%$ of these young drivers were involved in some sort of traffic accident after obtaining their driving license. From the median statistics, every one out of two accidents $(50 \%)$ is the respondents' fault. However, according to their driving style, approximately $59.7 \%$ of the respondents generally think that they are unlikely to be involved in an accident in the coming year. This can be linked to the phenomena of "overconfidence", as reported by Wohleber and Matthews [39]. Such an overconfidence attitude makes people underestimate risk, and this may contribute to risky behaviors such as speeding and traffic violations. The survey data clearly support the overconfident nature of young adults and their inverse performance on the road. 
Table 2. Young drivers' driving history.

\begin{tabular}{|c|c|c|}
\hline Item & Description & $\mathrm{N},(\%)$ \\
\hline \multirow[t]{2}{*}{ At what age did you learn how to drive? } & Below 17 & $71(28.9)$ \\
\hline & 17 and above & $175(71.1)$ \\
\hline \multirow{2}{*}{ Before you got your driver's license, did you ever drive without supervision? } & No & $139(54.9)$ \\
\hline & Yes & $114(45.1)$ \\
\hline \multirow[t]{4}{*}{ Who is the owner of the car you are driving? } & Father/Mother & $144(56.9)$ \\
\hline & Brother/Sister & $109(43.1)$ \\
\hline & Self & $217(85.1)$ \\
\hline & Others & $36(14.9)$ \\
\hline \multirow[t]{5}{*}{ How did you learn to drive? } & In a driving school & $115(45.5)$ \\
\hline & In the city streets & $32(12.6)$ \\
\hline & In the desert & $69(27.3)$ \\
\hline & Self-learned & $26(10.3)$ \\
\hline & Others & $11(4.3)$ \\
\hline \multirow[t]{4}{*}{ How many days do you drive a car per week? } & 3 to 6 days a week & $64(25.3)$ \\
\hline & Daily & $141(55.7)$ \\
\hline & Once a week & $15(5.9)$ \\
\hline & Twice a week & 33 (13.1) \\
\hline
\end{tabular}

Table 3. Young drivers' experience with crash involvement.

\begin{tabular}{|c|c|c|c|c|}
\hline Item & & $\mathbf{N}(\%)$ & Mean (SD) & Median (IQR) \\
\hline \multirow{2}{*}{ Have you ever been in car accidents } & Yes & $139(55.8)$ & \multirow{9}{*}{$\begin{array}{c}2.79 \\
(3.80) \\
1.68 \\
(2.61)\end{array}$} & \multirow{9}{*}{$\begin{array}{c}2.00 \\
(1.00-3.00) \\
1.00 \\
(0.50-2.00)\end{array}$} \\
\hline & No & $110(44.2)$ & & \\
\hline $\begin{array}{l}\text { How many accidents have you been involved in } \\
\text { as a driver since getting your driving license? }\end{array}$ & & $136(53.8)$ & & \\
\hline $\begin{array}{l}\text { From the accidents that you have been involved } \\
\text { in, how many were your fault? }\end{array}$ & & $137(54.2)$ & & \\
\hline \multirow{5}{*}{$\begin{array}{l}\text { Thinking generally about your driving style, how } \\
\text { likely are you to cause an accident next year? }\end{array}$} & Very Unlikely & $59(23.3)$ & & \\
\hline & Unlikely & $92(36.4)$ & & \\
\hline & Unsure & $76(30.0)$ & & \\
\hline & Likely & $13(5.1)$ & & \\
\hline & Very Likely & $7(2.8)$ & & \\
\hline
\end{tabular}

\subsection{Psychometric Properties}

The quality of the instrument, that is, the reliability measure, was measured using Cronbach's alpha and is shown in Table 4. The composite risky behavior, which consists of 40 questions, has an internal consistency of $\alpha$ 0.942. Among the seven factors describing risky behavior (DB 1 to DB 7), seatbelt usage had the highest internal consistency (0.898), followed by transient violations (0.873). The lowest fatigue was observed at $\alpha=0.735$. The obligation and personality factors have internal consistencies of $\alpha=0.880$ and $\alpha=0.470$, respectively. The data for overall risky behavior reports an exposure average of 2.24 per item, with the maximum being around 4.325. This shows that, in general, most drivers are involved in risky behaviors at some level. The same can be said about the obligation of traffic laws while driving, where the average exposure per item for an obligation is 2.33, with a maximum of five per item. These findings are consistent with those of other studies reported by Qatar [20,21]. For personality, the average score per item was 3.38, indicating that to some extent, the personality of the participant while driving played a role.

\subsection{Predicting Crash Involvement}

The relationship of the demographic attributes of the young drivers with the psychosocial-behavioral parameters is shown in Table 5. The significant factors were later used in the multiple regression analyses: linear and binary logistic regression. It was found that DB4 (fatigue) and DB6 (seatbelt) were highly associated with gender. When comparing males and females for DB4, the median score for males was 7.0 (interquartile 
range 4.0), and for females was 5.0 (interquartile range 4.0). It tends to show that male drivers do not take fatigue seriously. For DB6, the males had a median score of 4.0 compared to females scoring 3.0. This shows that males have low regard for using seat belts, which confirms previous findings $[38,40]$. In terms of nationality, the Qataris had a higher tendency to not use seat belts compared to the non-Qataris (median score of $4.0 \mathrm{vs}$. 3.0). However, the non-Qataris had a higher tendency for tailgating (median score of $5.0 \mathrm{vs}$. 4.0). From the analysis, it was found that drivers with tertiary education have higher risky behavior in terms of transient violation (DB1), mood driving (DB2), and fatigue (DB3) compared to drivers in high school. This can be related to the phenomenon of overconfidence, as explained by Ryan et al. [40]. An additional relationship was tested between questions "As a driver, have you ever been in car accidents?" and "Have you gotten any traffic violations during the last 12 months?" The findings showed a significant association between the two questions $(p=0.001) ; 66.7 \%(n=80$ out of 120$)$ of the respondents who had experienced traffic violations in the past 12 months were in car accidents. In contrast, $55.1 \%$ ( $n=70$ out of 127 ) of the respondents who did not receive any traffic violations did not experience any car accidents.

Table 4. Reliability measures of survey tool.

\begin{tabular}{|c|c|c|c|c|c|c|}
\hline Factors & $\mathbf{N}$ & $\begin{array}{l}\text { Cronbach's } \\
\text { Alpha }(\alpha)\end{array}$ & Score Range & Mean (SD) & $\begin{array}{l}\text { Median } \\
\text { (IQR) }\end{array}$ & Min-Max \\
\hline Overall Behavior & 40 & 0.942 & 40 to 200 & $89.55(25.10)$ & $\begin{array}{c}89.0 \\
(69.0-107.0)\end{array}$ & $40.0-173.0$ \\
\hline - DB1 (Transient Violations) & 17 & 0.873 & 17 to 85 & $29.90(9.08)$ & $\begin{array}{c}29.0 \\
(23.0-35.0)\end{array}$ & $17.0-64.0$ \\
\hline - DB 2 (Mood Driving) & 8 & 0.854 & 8 to 40 & $21.48(7.36)$ & $\begin{array}{c}21.0 \\
(16.0-27.0)\end{array}$ & $8.0-40.0$ \\
\hline - DB 3 (Speeding) & 4 & 0.839 & 4 to 20 & $10.79(3.86)$ & $\begin{array}{c}11.0 \\
(8.0-13.0)\end{array}$ & $4.0-20.0$ \\
\hline - DB 4 (Fatigue) & 3 & 0.735 & 3 to 15 & $6.79(2.82)$ & $\begin{array}{c}6.0 \\
(4.0-9.0)\end{array}$ & $3.0-15.0$ \\
\hline - DB 5 (Distracted Driving) & 4 & 0.857 & 4 to 20 & $11.52(4.37)$ & $\begin{array}{c}11.0 \\
(8.0-15.0)\end{array}$ & $4.0-20.0$ \\
\hline - DB 6 (Seatbelt Usage) & 2 & 0.898 & 2 to 10 & $4.62(2.78)$ & $\begin{array}{c}4.0 \\
(2.0-7.0)\end{array}$ & $2.0-10.0$ \\
\hline • DB 7 (Tailgating) & 2 & 0.780 & 2 to 10 & 4.45 (1.98) & $\begin{array}{c}4.0 \\
(3.0-6.0)\end{array}$ & $2.0-10.0$ \\
\hline Personality & 13 & 0.470 & 13 to 65 & 44.35 (5.87) & $\begin{array}{c}44.0 \\
(40.0-48.0) \\
\end{array}$ & $25.00-61.0$ \\
\hline Obligation & 9 & 0.880 & 9 to 45 & $20.95(7.40)$ & $\begin{array}{c}21.0 \\
(15.6-26.0)\end{array}$ & $9.0-45.0$ \\
\hline
\end{tabular}

Note: $\mathrm{DB}=$ risky driving behavior, $\mathrm{IQR}=$ inter quartile range, $\mathrm{SD}=$ standard deviation.

Table 5. Association between young drivers' demographic background and psychosocial-behavioral parameters.

\begin{tabular}{|c|c|c|c|c|c|c|c|c|c|}
\hline Item & & DB1 & DB2 & DB3 & DB4 & DB5 & DB6 & DB7 & Overall \\
\hline Gender* & $\begin{array}{c}\text { Male } \\
\text { Female }\end{array}$ & 0.484 & 0.191 & 0.338 & 0.002 & 0.600 & 0.029 & 0.280 & 0.617 \\
\hline Nationality * & $\begin{array}{c}\text { Qatari } \\
\text { Non-Qatari }\end{array}$ & 0.997 & 0.751 & 0.420 & 0.868 & 0.374 & 0.003 & 0.043 & 0.895 \\
\hline $\begin{array}{l}\text { Education } \\
\text { Level * }\end{array}$ & $\begin{array}{c}\text { Secondary } \\
\text { Tertiary }\end{array}$ & 0.008 & 0.039 & 0.090 & 0.011 & 0.044 & 0.380 & 0.226 & 0.007 \\
\hline
\end{tabular}

Note: Mann-Whitney test * was used at an alpha level of 0.05 .

The results in Table 6 explain the association between different psychosocial-behavioral domains/variables. All associations between the predictors were statistically significant 
$(p<0.01)$. All factors under the behavioral domains were significantly correlated $(p<0.001)$. The overall behavior $(\mathrm{OB})$ was found to be significantly associated (moderate) with the driver's personality $(p=0.000)$ and obligation $(p=0.000)$. In addition, the traffic accident factor $(\mathrm{Q} 3)$ was associated with all other factors $(p>0.05)$. Significant factors were considered in the multiple regression model. Two regression models were established: (i) a multiple linear regression model based on the number of faults when involved in an accident, and (ii) a multiple binary logistic regression model based on the response if the young driver was involved in a car accident. The multiple linear regression model was significant $(\mathrm{F}=2.571, p=0.007)$, and only DB1, DB2, DB3, DB4, DB5, DB7, obligation, and overall behavior were significant predictors (adjusted $\mathrm{R}^{2}=0.104$, symbolizing weak correlation and lack of fit for the model). The multiple linear regression model is shown in Equation (1). This value shows that these factors contribute approximately 10\% to traffic accidents (total variation for the dependent variable that could be explained by the independent variables).

Model: Number of faults when involved in an accident $=(-2.741)+0.073$

(transient violations) +0.061 (mood driving $)+0.190$ (speeding $)+0.234$

(fatigue) +0.155 (distracted driving) +0.313 (close following $)+0.028$

(overall behavior) +0.091 (obligation)

Table 6. Association between psychosocial-behavioral parameters and traffic accidents.

\begin{tabular}{|c|c|c|c|c|c|c|c|c|c|c|c|}
\hline & $\begin{array}{l}\text { Transient } \\
\text { Violation }\end{array}$ & $\begin{array}{c}\text { Mood } \\
\text { Driving }\end{array}$ & Speeding & Fatigue & $\begin{array}{l}\text { Distracted } \\
\text { Driving }\end{array}$ & $\begin{array}{l}\text { Seatbelt } \\
\text { Usage }\end{array}$ & Tailgating & Personality & Obligation & $\begin{array}{l}\text { Overall } \\
\text { (OB) }\end{array}$ & Q3 \\
\hline \multirow[t]{2}{*}{$\begin{array}{c}\text { Transient violations, } \\
\text { DB1 }\end{array}$} & - & & & & & & & & & & \\
\hline & 253 & & & & & & & & & & \\
\hline \multirow{2}{*}{$\begin{array}{l}\text { Mood driving, } \\
\text { DB2 }\end{array}$} & 0.665 & - & & & & & & & & & \\
\hline & $\begin{array}{c}0.000 \\
253\end{array}$ & 253 & & & & & & & & & \\
\hline \multirow[t]{2}{*}{ Speeding, DB3 } & 0.592 & 0.622 & - & & & & & & & & \\
\hline & 0.000 & 0.000 & 253 & & & & & & & & \\
\hline \multirow{3}{*}{ Fatigue, DB4 } & 0.561 & 0.492 & 0.341 & - & & & & & & & \\
\hline & 0.000 & 0.000 & 0.000 & & & & & & & & \\
\hline & 253 & 253 & 253 & 253 & & & & & & & \\
\hline \multirow{3}{*}{$\begin{array}{c}\text { Distracted driving } \\
\text { DB5 }\end{array}$} & 0.637 & 0.710 & 0.488 & 0.498 & - & & & & & & \\
\hline & 0.000 & 0.000 & 0.000 & 0.000 & & & & & & & \\
\hline & 253 & 253 & 253 & 253 & 253 & & & & & & \\
\hline \multirow[t]{3}{*}{ Seatbelt usage, DB6 } & 0.429 & 0.424 & 0.327 & 0.242 & 0.506 & - & & & & & \\
\hline & 0.000 & 0.000 & 0.000 & 0.000 & 0.000 & & & & & & \\
\hline & 253 & 253 & 253 & 253 & 253 & 253 & & & & & \\
\hline \multirow[t]{3}{*}{ Close following, DB7 } & 0.602 & 0.443 & 0.443 & 0.358 & 0.358 & 0.254 & - & & & & \\
\hline & 0.000 & 0.000 & 0.000 & 0.000 & 0.000 & 0.000 & & & & & \\
\hline & 253 & 253 & 253 & 253 & 253 & 253 & 253 & & & & \\
\hline \multirow[t]{3}{*}{ Personality } & -0.338 & -0.187 & -0.259 & -0.139 & -0.163 & -0.0183 & -0.164 & - & & & \\
\hline & 0.000 & 0.003 & 0.000 & 0.027 & 0.010 & 0.003 & 0.009 & & & & \\
\hline & 253 & 253 & 253 & 253 & 253 & 253 & 253 & 253 & & & \\
\hline \multirow[t]{3}{*}{ Obligation } & 0.543 & 0.461 & 0.453 & 0.309 & 0.402 & 0.216 & 0.362 & -0.323 & - & & \\
\hline & 0.000 & 0.000 & 0.000 & 0.000 & 0.000 & 0.001 & 0.000 & 0.000 & & & \\
\hline & 242 & 242 & 242 & 242 & 242 & 242 & 242 & 242 & 242 & & \\
\hline \multirow{3}{*}{ Overall behavior } & 0.899 & 0.860 & 0.709 & 0.653 & 0.804 & 0.551 & 0.605 & -0.306 & 0.554 & - & \\
\hline & 0.000 & 0.000 & 0.000 & 0.000 & 0.000 & 0.000 & 0.000 & 0.000 & 0.000 & 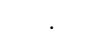 & \\
\hline & 253 & 253 & 253 & 253 & 253 & 253 & 253 & 253 & 242 & 253 & \\
\hline \multirow[t]{3}{*}{ Fault at accident (Q3) } & 0.356 & 0.235 & 0.262 & 0.316 & 0.342 & 0.062 & 0.221 & -0.012 & 0.240 & 0.341 & - \\
\hline & 0.000 & 0.006 & 0.002 & 0.000 & 0.000 & 0.473 & 0.010 & 0.891 & 0.005 & 0.000 & . \\
\hline & 137 & 137 & 137 & 137 & 137 & 137 & 137 & 137 & 137 & 137 & 137 \\
\hline
\end{tabular}

Tables 7 and 8 below indicate the relationship between behaviors, personality, and obligation with traffic accident involvement during the last 12 months. Gender, age, educational level, transient violations, speeding, fatigue, distracted driving, seatbelt usage, and overall behavior were considered in the model. Only age and sex were significant predictors. The multiple logistic regression model that can be developed from the above analysis is shown in Equation (2):

Model: Traffic accident $=(-8.564)+0.389($ Age $)+(-1.176)($ Gender $)$ 
Table 7. Causal relationship between psychosocial-behavioral parameters and number of faults when involved in an accident.

\begin{tabular}{cccccccc}
\hline Item & Unstandardized Coefficients & \multicolumn{2}{c}{ Standardized Coefficients } & \multicolumn{2}{c}{ 95.0\% CI for B } \\
\hline & $\boldsymbol{B}$ & Std. Error & Beta & $\boldsymbol{T}$ & Sig. & Lower Bound & Upper Bound \\
\hline Constant & -2.741 & 2.367 & & -1.158 & 0.249 & -7.424 & 1.943 \\
Transient violations & 0.073 & 0.023 & 0.263 & 3.164 & 0.002 & 0.027 & 0.118 \\
Mood driving & 0.061 & 0.029 & 0.178 & 2.102 & 0.037 & 0.004 & 0.119 \\
Speeding & 0.190 & 0.058 & 0.272 & 3.280 & 0.001 & 0.076 & 0.305 \\
Fatigue & 0.234 & 0.087 & 0.225 & 2.684 & 0.008 & 0.061 & 0.406 \\
Distracted driving & 0.155 & 0.049 & 0.262 & 3.159 & 0.002 & 0.058 & 0.252 \\
Seatbelt usage & 0.073 & 0.078 & 0.081 & 0.940 & 0.349 & -0.080 & 0.226 \\
Tailgating & 0.313 & 0.110 & 0.238 & 2.849 & 0.005 & 0.096 & 0.530 \\
Personality & 0.021 & 0.026 & 0.070 & 0.813 & 0.418 & -0.031 & 0.074 \\
Obligation & 0.091 & 0.028 & 0.271 & 3.265 & 0.001 & 0.036 & 0.146 \\
Overall behavior & 0.028 & 0.008 & 0.279 & 3.381 & 0.001 & 0.012 & 0.044 \\
\hline
\end{tabular}

Table 8. Causal relationship between psychosocial-behavioral parameters and number of faults when involved in an accident.

\begin{tabular}{cccccccc}
\hline Item & B & Std. Error & Wald & Df & Sig. & OR & 95\% CI for OR \\
\hline Constant & -8.564 & 1.838 & 21.708 & 1 & 0.000 & 0.000 & \\
Age & 0.389 & 0.090 & 18.853 & 1 & 0.000 & 1.476 & $1.238-1.759$ \\
Gender code & -1.176 & 0.330 & 12.654 & 1 & 0.000 & 0.309 & $0.162-0.590$ \\
Education level code & 0.175 & 0.352 & 0.246 & 1 & 0.620 & 1.191 & $0.597-2.376$ \\
Transient violations & 0.034 & 0.044 & 0.599 & 1 & 0.439 & 1.035 & $0.949-1.128$ \\
Speeding & 0.136 & 0.072 & 3.593 & 1 & 0.058 & 1.145 & $0.995-1.318$ \\
Fatigue & 0.017 & 0.079 & 0.045 & 1 & 0.833 & 1.017 & $0.871-1.187$ \\
Distracted driving & 0.115 & 0.069 & 2.765 & 1 & 0.096 & 1.122 & $0.980-1.284$ \\
Seatbelt usage & 0.108 & 0.077 & 1.972 & 1 & 0.160 & 1.114 & $0.958-1.296$ \\
Overall Behavior & -0.036 & 0.032 & 1.286 & 1 & 0.257 & 0.965 & $0.907-1.026$ \\
\hline
\end{tabular}

With multiple independent variables in the equation, the coefficient indicates the extent to which the dependent variable is expected to increase/decrease (affected, depending on the coefficient) when the independent variable increases by one, holding all the other independent variables constant. This study measured previous and collective psychosocial -behavioral parameters related to driving that influence the assessment of causality towards traffic accidents and violations. Thus, it has a temporal effect.

\section{Discussion}

From the analysis and with reference to Table 4, it is apparent that the young drivers in Qatar rated between "Hardly Ever" to "Occasionally" for the following risky driving traits: transient violation, mood driving, speeding, fatigue, distracted driving, seatbelt usage, and tailgating. Similar can be said for personality and obligation to abide by traffic laws. Based on these findings, this group of respondents is obviously not high-risk takers while on the road. This is because of the sampling approach adopted in this study. From the regression models, it was found that the likelihood of committing traffic violations is associated with driving behavior and attitude to abide by traffic laws. There was no strong association found with personality traits, which contradicts the findings reported by [33-36].

In a study conducted by $\mathrm{Al}$ Reesi [30], he found that nearly $60.7 \%$ of those involved in traffic accidents were at fault. These are close to the findings obtained in Qatar, which reported that $50 \%$ were at fault. With regard to gender, young Omani males had a higher likelihood of being involved in accidents than females. This is the opposite of what we found in Qatar. Young males in Qatar are only 0.309 times as likely as females to be involved in an accident and approximately $70 \%$ less likely to have an accident than females. This result can be influenced by the relatively high percentage of female drivers who responded to the questionnaire. Female drivers are prone to accidents connected to maneuvering and control of traffic situations, whereas males are mostly connected to 
high-speed accidents, resulting in severe injuries and fatalities [41]. Based on the responses, the male respondents were not really engaged in high-speed driving, indicating that fewer accidents were reported. The older young drivers are more involved in traffic accidents than the younger drivers, i.e., around 1.5 times more likely. Moreover, a young male driver is 3.2 times less likely to be involved in traffic accidents than a female driver. The current study showed a significant association between traffic violations and car accidents. This suggests that risky driving behavior, which causes traffic violations, is closely associated with traffic accidents. Similar findings were found by Al-Reesi [30], who examined young Omani drivers.

The following are the responses to the hypotheses posted at the beginning of this study:

Hypothesis 1. Positive personality and positive obligation towards traffic laws have a significant positive impact on safe driving behavior (linked to overall behavior).

Outcome: The study found that a positive obligation towards traffic laws has a positive impact on safe driving behavior. However, the role of personality was not well understood from the statistical analysis, and it remains inconclusive.

Hypothesis 2. Positive personality and positive obligation towards traffic laws have a significant impact on reducing accident involvement.

Outcome: A positive obligation towards traffic laws has a significant impact on reducing accident involvement. The role of personality traits was not found to be an important influencing factor for risky behaviors and car accidents. This is contrary to the findings of other researchers [42], in which personality traits are indeed significant predictors of risk-taking while driving.

Hypothesis 3. Each driving behavior factor $(D B)$ has a significant impact on accident involvement.

Outcome: Based on the statistical analysis, driving behavior has a significant impact on the number of traffic violations, but not on accidents.

Hypothesis 4. Demographics traits have significant positive impacts on accident involvement.

Outcome: The only demographic traits that had a positive impact on accident involvement were the age of the driver and gender.

\subsection{Limitations}

The study presented here is based on a survey conducted with young adult drivers in Qatar and may not be reflective of the wider driving population. Some disparities may exist between the numbers presented here and the official crash records. The final response rate was lower than the initial estimated sample size. There is also the potential for social desirability bias due to the sampling technique adopted in this study. Another potential disadvantage is a lack of realism. The results of this study are influenced by the relatively high percentage of young female drivers as respondents, considering the usual distribution of drivers based on gender, not only in Arabic countries but in general, are male. Despite the above limitations, this study has to some extent, revealed the risky driving behavior among young adults in Qatar.

\subsection{Future Work and Recommendations:}

The results provide support for possible intervention strategies that can be employed by driver education programs to reduce any sort of aggressive driving. A longitudinal research design would allow for an examination of the actual driving behavior of young adults, and perhaps this can be done by using telematics data. 


\section{Conclusions}

The psychometric properties of the tool used in this study were found to be valid and reliable. It was found that $55.8 \%$ of these young drivers were involved in some sort of traffic accident after obtaining their driving license; from these, every 1 out of 2 accidents is the fault of the young driver. The older young drivers are more involved, i.e., around 1.5 times more likely, to be involved in traffic accidents than the younger drivers. Moreover, a young male driver is 3.2 times less likely to be involved in traffic accidents than a female driver. In addition, males are only 0.309 times as likely as females to be involved in an accident and approximately $70 \%$ less likely to have an accident versus females. From the results obtained here, the self-study tool has demonstrated that young adult drivers in Qatar do have some risky driving behavior issues accompanied by a tendency to not comply with traffic regulations while driving. Some of these young drivers are controlled by their aggressive personalities while on the road. Some interventions are required to improve driving behavior in Qatar, such as driving apps that are able to monitor and provide corrective feedback.

Author Contributions: Conceptualization, F.T.; methodology, F.T.; validation, M.I.M.I.; formal analysis, M.I.M.I.; investigation, B.G.; resources, B.G.; data curation, B.G.; writing-original draft preparation, F.T. and M.I.M.I.; writing-review and editing, M.I.M.I. and B.G.; supervision, F.T.; project administration, F.T.; funding acquisition, F.T. All authors have read and agreed to the published version of the manuscript.

Funding: This research and APC was funded by the Qatar National Research Fund (QNRF), grant number NPRP12S-0129-190017.

Institutional Review Board Statement: The study was conducted in accordance with the guidelines of the Declaration of Helsinki and approved by the institutional review board (or ethics committee) of Qatar University (QU-IRB 1329-EA/20 approved on 2 June 2020).

Informed Consent Statement: Informed consent was obtained from all subjects involved in the study.

Data Availability Statement: The data presented in this study are available on request from the corresponding author. The data are not publicly available due to some restrictions, and they are only available on reasonable request.

Acknowledgments: This study was made possible by an NPRP grant\# NPRP12S-0129-190017 from the Qatar National Research Fund (a member of the Qatar Foundation). The findings of this study are solely the responsibility of the authors. The authors would also like to thank the Social and Economic Survey Research Institute (SESRI) at Qatar University for supporting the use of the Qualtrics survey tool used in this study.

Conflicts of Interest: The authors declare no conflict of interest.

\section{References}

1. Road Traffic Injuries. World Health Organization. 2021. Available online: https://www.who.int/news-room/fact-sheets/detail/ road-traffic-injuries (accessed on 31 August 2021).

2. $\quad$ Blincoe, L.J.; Miller, T.R.; Zaloshnja, E.; Lawrence, B.A. The Economic and Societal Impact of Motor Vehicle Crashes 2010 (Revised); National Highway Traffic Safety Administration: Washington, DC, USA, 2015.

3. Houston, J.; Harris, P.; Norman, M. The aggressive driving behaviour scale: Developing a self-report measure of unsafe driving practices. N. Am. J. Psychol. 2003, 5, 269-278.

4. Iversen, H. Risk-taking attitudes and risky driving behaviour. Transp. Res. Part F 2004, 7, 135-150. [CrossRef]

5. Monselise, M.; Liang, O.S.; Yang, C.C. Identifying Important Risk Factors Associated with Vehicle Injuries Using Driving Behavior Data and Predictive Analytics. In Proceedings of the 2019 IEEE International Conference on Healthcare Informatics (ICHI), Xi'an, China, 10-13 June 2019; pp. 1-10.

6. Danish, F.; Juhasz, J. Statistical Evaluation of Risky Driver Behavior Factors that Influence Road Safety based on Drivers Age and Driving Experience in Budapest and Islamabad. Eur. Transp. Trasp. Eur. 2020, 80, 1-18.

7. Farooq, D.; Moslem, S.; Tufail, R.F.; Ghorbanzadeh, O.; Duleba, S.; Maqsoom, A.; Blaschke, T. Analyzing the Importance of Driver Behavior Criteria Related to Road Safety for Different Driving Cultures. Int. J. Environ. Res. Public Health 2020, $17,1893$. [CrossRef] [PubMed] 
8. Tzortzi, A.; Kapetanstrataki, M.; Evangelopoulou, V.; Behrakis, P. Driving Behavior That Limits Concentration: A Nationwide Survey in Greece. Int. J. Environ. Res. Public Health 2021, 18, 4104. [CrossRef]

9. Freire, M.; Gauld, C.; McKerral, A.; Pammer, K. Identifying Interactive Factors That May Increase Crash Risk between Young Drivers and Trucks: A Narrative Review. Int. J. Environ. Res. Public Health 2021, 18, 6506. [CrossRef]

10. Scott-Parker, B.; Hyde, M.; Watson, B.; King, M. Speeding by young novice drivers: What can personal characteristics and psychosocial theory add to our understanding? Accid. Anal. Prev. 2013, 50, 242-250. [CrossRef]

11. Fu, H.; Wilmot, C.G. Effect of Passenger Age and Gender on Fatal Crash Risks of Young Drivers. TRB 2008 Annu. Meet. CD-ROM 2007, 2078, 33-40. Available online: https://www.ltrc.lsu.edu/pdf/2008/08-0617.PDF (accessed on 30 December 2021).

12. Fernandes, R.; Hatfield, J.; Job, R.S. A systematic investigation of the differential predictors for speeding, drink-driving, driving while fatigued, and not wearing a seat belt, among young drivers. Transp. Res. Part F Traffic Psychol. Behav. 2010, 13, 179-196. [CrossRef]

13. Neyens, D.M.; Boyle, L.N. The influence of driver distraction on the severity of injuries sustained by teenage drivers and their passengers. Accid. Anal. Prev. 2008, 40, 254-259. [CrossRef] [PubMed]

14. Shope, J.T. Influences on youthful driving behavior and their potential for guiding interventions to reduce crashes. Inj. Prev. 2006, 12, i9-i14. [CrossRef] [PubMed]

15. Fu, H.; Wilmot, C.G. Effect of Passenger Age and Gender on Fatal Crash Risks of Young Drivers. Transp. Res. Rec. J. Transp. Res. Board 2008, 2078, 33-40. [CrossRef]

16. Lipovac, K.; Đerić, M.; Tešić, M.; Andrić, Z.; Marić, B. Mobile phone use while driving-literary review. Transp. Res. Part F Traffic Psychol. Behav. 2017, 47, 132-142. [CrossRef]

17. Montuori, P.; Sarnacchiaro, P.; Nubi, R.; Di Ruocco, D.; Belpiede, A.; Sacco, A.; De Rosa, E.; Triassi, M. The use of mobile phone while driving: Behavior and determinant analysis in one of the largest metropolitan area of Italy. Accid. Anal. Prev. 2021, 157, 106161. [CrossRef] [PubMed]

18. Shaaban, K.; Gaweesh, S.; Ahmed, M.M. Characteristics and mitigation strategies for cell phone use while driving among young drivers in Qatar. J. Transp. Health 2018, 8, 6-14. [CrossRef]

19. Shaaban, K.; Abdelwarith, K. Understanding the association between cell phone use while driving and seat belt noncompliance in Qatar using logit models. J. Transp. Saf. Secur. 2018, 12, 292-308. [CrossRef]

20. Awadalla, M.; Tallon, L.; Peralta, R.; El-Menyar, A.; Al-Thani, H.; Consunji, R. 868 The disproportionate risk of young drivers for road traffic injury and fatality in Qatar: Evidence for policy. Inj. Prev. 2016, 22, A309-A310. [CrossRef]

21. Soliman, A.; Alhajyaseen, W.; Alfar, R.; Alkaabi, I. Changes in Driving Behavior Across Age Cohorts in an Arab Culture: The Case of State of Qatar. Procedia Comput. Sci. 2018, 130, 652-659. [CrossRef]

22. Casado-Sanz, N.; Guirao, B.; Galera, A.L.; Attard, M. Investigating the Risk Factors Associated with the Severity of the Pedestrians Injured on Spanish Crosstown Roads. Sustainability 2019, 11, 5194. [CrossRef]

23. Timmermans, C.; Alhajyaseen, W.; Al Mamun, A.; Wakjira, T.; Qasem, M.; Almallah, M.; Younis, H. Analysis of road traffic crashes in the State of Qatar. Int. J. Inj. Control. Saf. Promot. 2019, 26, 242-250. [CrossRef] [PubMed]

24. Caffò, A.O.; Tinella, L.; Lopez, A.; Spano, G.; Massaro, Y.; Lisi, A.; Stasolla, F.; Catanesi, R.; Nardulli, F.; Grattagliano, I.; et al. The Drives for Driving Simulation: A Scientometric Analysis and a Selective Review of Reviews on Simulated Driving Research. Front. Psychol. 2020, 11, 917. [CrossRef]

25. Reason, J.T.; Manstead, A.S.R.; Stradling, S.G.; Baxter, J.S.; Campbell, K. Errors and violations on the road: A real distinction? Ergonomics 1990, 33, 1315-1332. [CrossRef] [PubMed]

26. Parker, D.; Stradling, S.G.; Manstead, A. Modifying beliefs and attitudes to exceeding the speed limit: An intervention study based on the theory of planned behaviour. J. Appl. Soc. Psychol. 1996, 26, 1-19. [CrossRef]

27. Lajunen, T.; Summala, H. Effects of driving experience, personality, and driver's skill and safety orientation on speed regulation and accident. In Traffic and Transport Psychology, Theory and Application; Rothengatter, T., Vaya, E.C., Eds.; Emerald Group Publishing Limited: Qxford, UK, 1997; pp. 283-294.

28. Scott-Parker, B.; Watson, B.; King, M.J. The risky behaviour of young drivers: Developing a measurement tool. In Proceedings of the 24th Canadian Multidisciplinary Road Safety Conference, Niagara Falls, ON, Canada, 6-9 June 2010.

29. af Wåhlberg, A.; Dorn, L.; Kline, T. The Manchester Driver Behaviour Questionnaire as a predictor of road traffic accidents. Theor. Issues Ergon. Sci. 2011, 12, 66-86. [CrossRef]

30. Al Reesi, H.; Freeman, J.; Davey, J.; Al Adawi, S.; Al Maniri, A. Measuring risky driving behaviours among young drivers: Development of a scale for the Oman setting. Transp. Res. Part F Traffic Psychol. Behav. 2018, 55, 78-89. [CrossRef]

31. af Wahlberg, A.; Dorn, L.; de Winter, J.C.F.; Dodou, D.; Freeman, J. Commentaries and responses to "The Driver Behav-iour Questionnaire as a Predictor of Accidents: A Meta-analysis". J. Saf. Res. 2012, 43, 83-99. [CrossRef] [PubMed]

32. Wishart, D.E.; Freeman, J.E.; Davey, J.D.; Wilson, A.; Rowland, B.D. When non-significance may be significant: Lessons learned from a study of the development, implementation and evaluation of a fleet risk assessment tool. In Driver Behaviour and Training; Dorn, L., Ed.; Ashgate: Surrey, UK, 2012; pp. 197-214.

33. Ulleberg, P.; Rundmo, T. Personality, attitudes and risk perception as predictors of risky driving behaviour among young drivers. Saf. Sci. 2003, 41, 427-443. [CrossRef] 
34. Spano, G.; Caffò, A.O.; Lopez, A.; Mallia, L.; Gormley, M.; Innamorati, M.; Lucidi, F.; Bosco, A. Validating Driver Behavior and Attitude Measure for Older Italian Drivers and Investigating Their Link to Rare Collision Events. Front. Psychol. 2019, 10, 368. [CrossRef]

35. Society for Risk Analysis (SRA). Impulsive, angry personalities more prone to aggressive driving, accidents, study finds. ScienceDaily, 28 April 2015.

36. Roseborough, J.E.; Wickens, C.M.; Wiesenthal, D.L. Retaliatory aggressive driving: A justice perspective. Accid. Anal. Prev. 2021, 162, 106393. [CrossRef]

37. Alison, G. Non-Probability Sampling. Encycl. Soc. Meas. 2005, 2, 859-864.

38. Mohamed, M.; Bromfield, N.F. Attitudes, driving behavior, and accident involvement among young male drivers in Saudi Arabia. Transp. Res. Part F Traffic Psychol. Behav. 2017, 47, 59-71. [CrossRef]

39. Wohleber, R.W.; Matthews, G. Multiple facets of overconfidence: Implications for driving safety. Transp. Res. Part F Traffic Psychol. Behav. 2016, 43, 265-278. [CrossRef]

40. Susan, D.; Ali, A.Z. "Seatbelts don't save lives": Discovering and targeting the attitudes and behaviors of young Arab male drivers. Accid. Anal. Prev. 2018, 121, 185-193.

41. Laapotti, S.; Keskinen, E. Has the difference in accident patterns between male and female drivers changed between 1984 and 2000? Accid. Anal. Prev. 2004, 36, 577-584. [CrossRef]

42. Baran, P.; Zieliński, P.; Dziuda, Ł. Personality and temperament traits as predictors of conscious risky car driving. Saf. Sci. 2021, 142, 105361. [CrossRef] 